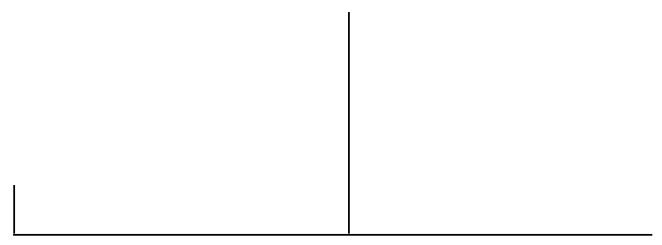

Rev. Latinoam. Psicopat. Fund., São Paulo, v. 13, n. 2, p. 190-206, junho 2010

\title{
Violência familiar: obesidade mórbida e função ômega
}

\author{
Maria do Carmo Cintra de Almeida-Prado \\ Terezinha Féres-Carneiro
}

Este estudo objetiva explorar aspectos psicológicos de obesos mórbidos e se baseia em treze casos atendidos em avaliação psicodiagnóstica. Para este trabalho, foram utilizadas suas histórias de vida, conforme relatadas por eles durante as entrevistas. O material coletado foi analisado a partir do referencial psicanalítico. Conclui-se que a obesidade mórbida é uma patologia dos estados-limite, que diz respeito ao ômega somático, em que há perturbações na continência psíquica e nos processos de transformação.

Palavras-chave: Obesidade mórbida, função ômega, violência familiar, transmissão psíquica 
A questão da obesidade apresenta-se como um desafio para os psicoterapeutas, particularmente quando se trata de obesidade mórbida. Com a nova expectativa de vida oferecida pela cirurgia bariátrica, os aspectos psicológicos dos obesos mórbidos parecem ser considerados a partir da perspectiva de suas condições psíquicas, se favoráveis ou não para a realização da cirurgia e para o sucesso do pós-operatório. No entanto, o que leva uma pessoa a chegar à condição de obeso mórbido? A resposta imediata - e mais simplista - diz respeito à ingesta excessiva e falta de exercícios físicos. Tal entendimento orienta um tradicional programa de assistência voltado para dietas restritivas e a prática de atividades físicas, programa este comumente fadado ao fracasso e retomado sistematicamente, com novos fracassos e mais aumento de peso. Entra então em pauta a perspectiva da reeducação alimentar, igualmente difícil de ser levada a contento.

Ninguém nasce obeso mórbido, ainda que excepcionalmente haja casos de bebês que nasçam com peso bastante acima do habitual devido a tumor ou lesão na região ventromedial do hipotálamo. Para se chegar à obesidade mórbida, o sujeito passou pelo estado de pré-obeso, de obeso I, II e, finalmente, III, quando o IMC é igual ou superior a 40, caracterizando-se assim a morbidade da obesidade. Mas quem é o obeso mórbido? Referido como uma pessoa sem controle, estigmatizada ou vítima de preconceito, assim sendo, desfavorecida quanto à aceitação social (Gaspar, 2003; Benedetti, 2003), na verdade ele é muito pouco conhecido.

As causas da obesidade são referidas como multideterminadas. De acordo com Loli (2000), elas são classificadas em sete tipos: neurológica, endócrina, genética, de inatividade física, farmacológica, ambiental e psicológica ou emocional. A estas, podemos acrescentar o abuso sexual na infância, em se tratando de meninas. Segundo Bentovim (1992), as mesmas, vítimas de abuso sexual, regridem à fase oral devido aos conflitos com a genitalidade, e o prazer passa a ser obtido por meio da ingesta de alimentos. Quanto aos meninos, o autor assinala que estes se tornam mais agressivos. 


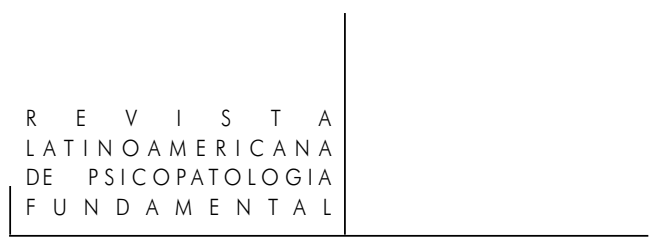

O presente estudo se concentra basicamente nos aspectos psicológicos da obesidade mórbida e se baseia em casos atendidos em setor de psicodiagnóstico de serviço de psiquiatria de um hospital universitário público. O sujeito, em seu desenvolvimento, necessita de um outro que lhe dispense cuidados e lhe ofereça acolhimento afetivo. Assim, será na intersubjetividade que, em circunstâncias suficientemente boas, será promover-se-á a vida.

\section{Os espaços intrapsíquicos e intersubjetivos e a promoção da vida}

Para poder sobreviver e se desenvolver, o bebê depende de um outro, basicamente sua mãe, como fonte de nutrição tanto física como emocional. Ao procurar satisfazer suas necessidades fisiológicas e afetivas, ele busca objetos. $\mathrm{O}$ bebê é um ser que sonha com o objeto que o satisfaz, sua mãe, ela própria sonhando com a satisfação dele (Ruffiot, 1981). Desta forma se promove a vida. Por outro lado, ter necessidades e reconhecer que depende de alguém para satisfazê-las pode dar origem a intensos conflitos, que levam a tentativas mais ou menos bem-sucedidas de ataques a si mesmo e a qualquer objeto capaz de oferecer satisfação. Os elos de ligação (Bion, 1967/1988) sendo atacados, investe-se contra a vida.

Ao tratar das séries complementares, Freud tanto busca o determinismo das neuroses (1916-1917) quanto aborda a questão do traumatismo (1939). No primeiro caso, o fator endógeno é representado pelos pontos de fixação, que são variáveis para cada sujeito e decorrem da própria constituição e das vivências infantis, enquanto o exógeno deriva das situações de frustração. Já as situações traumáticas reais têm origem exógena e seus efeitos, mais do que perturbadores, podem ser profundamente desorganizadores. Brette (2002) comenta que a expressão "traumatismo real" é discutível, pois pode ser contraposta a traumatismos "fictícios", "imaginários" ou mesmo "mentirosos", no entanto, diz a autora, qualquer traumatismo, não importando sua origem, endógena ou exógena, é "real" quanto a seus efeitos. Assim sendo, sofrer ou presenciar agressões físicas e psíquicas, particularmente na infância e, sobretudo, em família, bem como ser tratado com negligência, corresponde a fatos reais violentos cujas consequências são patogênicas.

Brette afirma que muitos discípulos de Freud, ao não levarem em conta a oscilação presente entre realidade e fantasia, ao longo de sua obra, desconfiam a respeito da realidade e optam pela precedência da fantasia e da onipotência de pensamento. Na atualidade, há analistas (Rouyer, 1992/1997; Gabel et al. 1995; Carneiro, 2005) que preferem levar em consideração o real em sua brutalidade 
traumática, o que não dispensa a longa elaboração da atividade fantasiosa mobilizada pela experiência. Apoiando-se na concepção econômica do trauma, tal como definida por Freud em 1920, reconhecem que um evento, por sua natureza e intensidade, pode ter um efeito demolidor, embora não possa ser reduzido a uma verdade objetivável.

De acordo com Freud (1912), o destino de um homem é determinado por fatores inatos (constitucionais) e acidentais, isto é, por talento e sorte - e raramente ou nunca por um só destes poderes. Em cada caso individual, faz-se necessário avaliar a cota que cabe a cada um deles, segundo a proporção variável em que estejam presentes, sendo que a própria constituição pode ser encarada como um precipitado dos efeitos acidentais produzidos na cadeia infinitamente longa dos antepassados. Têm-se aqui as dimensões inter e transgeracional de elementos que interferem com o destino pessoal, pela articulação dos espaços intrapsíquico e intersubjetivo, atravessados pela realidade psíquica (Kaës, 2005).

Ao considerar os sofrimentos psíquicos e as patologias com as quais se tem que lidar na contemporaneidade, Kaës (2005) propõe descrevê-las como patologias dos "estados-limite", decorrentes de perturbações ou falta de continência psíquica, de falhas na capacidade de ligação e de desligamento, bem como nos processos de transformação. Tomadas em conjunto, diz serem patologias da transmissão da vida psíquica entre as gerações, tratando-se, em sua maioria, de patologias do narcisismo, do originário e da simbolização primária, portanto, do vínculo intersubjetivo. Assim sendo, o desenvolvimento da capacidade de simbolização, transformação e superação - com a criação da vida psíquica, e também da relacional e da cultural - é tributário de condições que favoreçam encontrar prazer com o próprio corpo e com as primeiras atividades psíquicas, bem como o acesso à capacidade de pensar. Para tanto, estão em questão as formações e os processos intermediários e suas relações entre continuidade e ruptura, permanência e transformação. Quando esta função de mediação se dá de forma suficientemente boa, a partir de uma experiência subjetiva e intersubjetiva, calcada na tolerância e na confiança, ela favorece a articulação entre elementos, particularmente aqueles que se encontram tensos ou conflitados.

\section{Obesidade mórbida: uma patologia do narcisismo?}

A imobilização e o isolamento que progressivamente envolvem a vida dos grandes obesos fazem pensar que a obesidade mórbida é, basicamente, uma patologia do narcisismo. Se comer é condição precípua para a continuidade da vida, neste caso, se torna uma ameaça de morte. Trata-se de uma relação "louca" com 


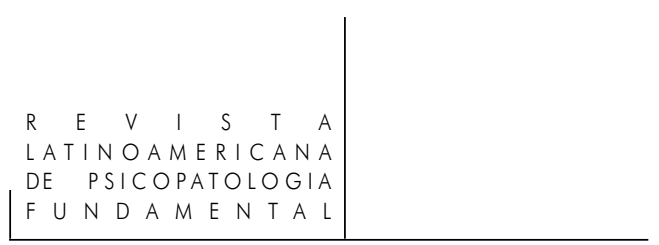

a comida e com o corpo, o que nos leva a considerar que a personalidade do obeso mórbido esteja dividida em uma parte psicótica e outra não psicótica, conforme descritas por Bion (1967).

Ainda que uma parte da personalidade possa estabelecer contato com a realidade e manter certo grau de funcionamento adequado, outra se vê encapsulada por meio de estratégias defensivas poderosas, de cunho perverso ou psicótico, que promovem o que Steiner (1993) denominou de refúgio psíquico, e que corresponde a uma área do psiquismo onde a realidade não precisa ser encarada, na qual fantasia e onipotência coexistem sem restrições e, desta forma, onde tudo é permitido. É justamente esta característica que torna o refúgio tão atraente, mas o alívio fornecido por ele é obtido à custa de isolamento, estagnação e retraimento.

A questão é que a parte psicótica da personalidade tem mais chances de promover ataques destrutivos contra o próprio psiquismo e, assim, há algo de letal e autodestrutivo na psicodinâmica dos grandes obesos, que ameaça sua integridade e que se apresenta como muito difícil de ser tratado e contido. As estratégias defensivas das quais lançam mão visam neutralizar e controlar sua destrutividade primitiva, não importando qual seja sua origem, dando-se uma formação de compromisso, pois ao mesmo tempo em que elas apontam para sua manifestação, também se mostram como uma defesa contra ela.

\section{A manifestação de forças destrutivas no psiquismo}

O psiquismo dominado por uma organização narcísica mantém prisioneiros seus aspectos sadios por meio da onipotência e destrutividade, que impedem seu crescimento e prejudicam a possibilidade de se relacionar com objetos que tenham condições de ajudá-lo em seu desenvolvimento e evolução, empurrando-o em direção à morte (Rosenfeld, 1971).

As relações objetais narcísicas podem ser entendidas como defesa contra o reconhecimento da existência da separação entre o self e o objeto, o que levaria a sentimentos de dependência com relação a este, sobretudo se ele for capaz de nutrir física e emocionalmente, e portanto de promover a vida. Estas qualidades despertariam sentimentos de humilhação, e estimulariam a hostilidade contra o objeto. Tal compreensão levou Rosenfeld (1965) a conceber o narcisismo como uma defesa contra a inveja. Uma distinção será feita pelo autor (1987) entre o narcisismo baseado na inveja primária, em que predomina a destrutividade - chamado de "narcisismo de pele grossa" - e aquele resultante de vivências traumáticas na infância, referido como "narcisismo de pele fina". Este decorre da falta 


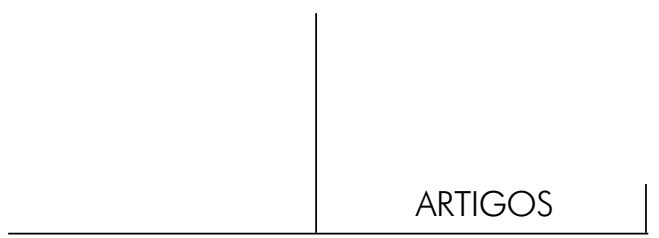

de cuidados apropriados por parte do objeto responsável pela maternagem, o que é uma experiência traumática, e se caracteriza pela incapacidade de estabelecer relações objetais satisfatórias.

O objeto - mostrando-se falho em sua capacidade de conter, de assimilar e digerir as emoções e as experiências, primeiramente do bebê, depois da criança ainda dependente - favorecerá a intensificação das angústias de aniquilamento. Provocará também prejuízo em sua capacidade de simbolização, porque esta resulta da criação de significados novos que se integram em um todo mais harmonioso a partir da relação com um outro. Desta forma, as experiências não reconhecidas em seu significado emocional impedem que o sujeito desenvolva condições próprias para ser mais compreensivo e tolerante a respeito de seus próprios estados psíquicos. O desenvolvimento de relações íntimas se vê prejudicado e a atividade de simbolização se apresenta incompleta, o que faz com que as vivências depressivas, frustrações, ambivalências, conflitos diversos e a dor psíquica decorrente se tornem insuportáveis, pela falta de continência psíquica e de recursos internos para lidar com eles de forma mediada, de modo a favorecer sua elaboração e transformação. As experiências emocionais passam então a ser evacuadas. Sem proteção, o sujeito se mantém vítima de sua própria organização psíquica.

\section{As falhas na continência familiar e seus efeitos: a função ômega}

Decherf (2003) assinala que as angústias evoluem em função do meio e de muitos outros fatores, entre eles o constitucional e o contrato narcísico, ao nascimento, que envolve as gerações. O recém-nascido, devido a sua urgência vital, precisa encontrar um objeto primário capaz de ajudá-lo a gerenciar suas angústias, as quais consegue ultrapassar pelas respostas relativamente satisfatórias do meio, derivadas de um movimento pulsional de vida. Assim sendo, em condições suficientemente favoráveis, a prevalência da função alfa (Bion, 1967) assegura a instalação de vínculos de vida, o que favorece a introjeção de um bom objeto que, no entender de Klein (1963), constituirá o núcleo do ego, propiciando que o sujeito venha a ter condições de gerenciar ele próprio suas angústias.

Alfa e ômega são a primeira e a última letra do alfabeto grego, respectivamente. Contraposta à função alfa, Decherf conceitua como ômega a defesa construída pelo sujeito contra as angústias de morte quando elas são muito intensas. Devido à vulnerabilidade real do bebê, considera como um ômega normal a confrontação inevitável, imprescindível para sua sobrevivência, com as angústias de 
morte presentes desde o início da vida. A dominante normal deste combate, que depende de como a criança seja tratada nesta primeira fase de seu desenvolvimento, é aquela voltada para a vida, isto é, as angústias bem tratadas pelo meio maternal e familiar poderão se tornar aceitáveis e integráveis pela criança. Caso contrário, ela se verá dominada pela angústia de morte e sua vida relacional se caracterizará por um vínculo de sobrevivência.

A insuficiência no trato com as angústias de morte dá lugar, então, a verdadeiras construções defensivas chamadas por Decherf de ômega: trata-se de bebês e de famílias-ômega. Estes bebês - inconsoláveis, rígidos ou voltados para si mesmos - não podem mais se nutrir de esperança e de relação para se apaziguarem, e constroem um ômega patológico para se defenderem. O autor distingue as defesas ômegas passageiras das patológicas, que se apresentam como organizadoras da vida psíquica. As primeiras correspondem a um ômega mitigado e se dão como meio de escapar ao sofrimento, por certo tempo, graças a alguns recursos de sobrevida, através de uma regressão particular, que favorece o surgimento de confusões psíquicas passageiras ou de estratégias e manobras perversas ocasionais. Já o ômega patológico é mais primário e decorre de falhas graves da função alfa, correspondendo a organizações defensivas instaladas, estáveis e duráveis: o vínculo alfa não podendo ser introjetado, com o decorrente prejuízo na capacidade de simbolização, elaboração e transformação, acaba sendo substituído pelo vínculo de sobrevida ou vínculo ômega, que passa então a prevalecer. Nessas circunstâncias, embora tenha sido possível escapar do desmoronamento psicótico, a fixação na indiferenciação como padrão relacional indica não ter havido meios para estabelecer defesas mais adequadas, próprias do sujeito separado e individuado.

Os funcionamentos familiares confusionais e perversos, no entender de Decherf, constituem as principais modalidades defensivas ômegas observadas em terapias de casal e de família. Para sobreviver psiquicamente, o sujeito "ômega" deve exercer seu domínio sobre um outro, que lhe é indispensável como complemento narcísico, ainda mais porque lhe cabe preencher uma continência deficitária, criando com ele um vínculo ômega, destinado a dominá-lo. Este vínculo de dominação constitui um elemento necessário a sua sustentação psíquica. $\mathrm{O}$ sujeito ômega, apresentado por Decherf, parece corresponder ao perverso narcísico conceituado por Racamier (1988), ainda que ele possa construir ativamente várias formas de defesas a partir da indiferenciação primária, visando garantir a perenidade da confusão e, portanto, de um "estado-bebê".

As falhas na continência familiar podem se dar por falta (subcontinência), por excesso (supercontinência), ou ainda por uma alternância entre eles (continência paradoxal). Entre os fatores que favorecem a subcontinência estão a de- 
pressão ou doença mental dos pais, sua carência e/ou ausência, violência entre eles, pais anticasal ou casais antifamília, o que favorece a prevalência das angústias de separação e vivências persecutórias, levando o sujeito a buscar dominar suas necessidades psíquicas e afetivas. Já entre os fatores favorecedores da supercontinência encontram-se pais culpados e excessivamente reparadores ou tolerantes, injustiça e violência familiares, vínculos muito apertados, invasão e falhas narcísicas, o que acarreta diversas formas de angústia: intrusão, perseguição, sufocamento e enclausuramento. Tais situações favorecem a indiferenciação primária, a impossibilidade de renunciar e a confusão. Na continência paradoxal todos esses fatores favorecedores e suas consequências aparecem alternadamente. Esta oscilação caracteriza a posição narcísico-paradoxal (Caillot e Decherf, 1982), que representa uma defesa contra as angústias catastróficas de separação e de união e expressa o desejo, tanto para o sujeito quanto para o casal ou para a família, de estar ao mesmo tempo separado e unido, levando os autores a afirmar que, nesses casos, viver junto é impossível, mas separar é mortal.

O ômega patológico é uma construção defensiva da ordem do agir e do comportamental e envolve muitas variedades clínicas. A proximidade psíquica com a morte é uma constante, observável através de passagens ao ato ou de encenações angustiantes e perigosas que precisam ser dominadas.

O sujeito busca reencontrar para si um envelope, quente ou frio, ao procurar reconstituir, nas relações com o outro, na escolha de seu meio profissional, de suas atividades, na organização mesmo de sua vida, um meio maternante. Decherf relaciona a subcontinência à continência fria e a supercontinência, à quente. Entre essas organizações, o autor assinala o deslocamento da relação sobre um objeto inerte, não vivo, seja ele um objeto quente suscetível de dar calor, como álcool, tabagismo, inalação e injeção de drogas, por exemplo - e aqui cremos poder incluir a comida - ou frio, como fetiches, exposição a riscos, tal como subidas em cumes montanhosos gelados, ou ainda com uma alternância de quente/frio, como travessias solitárias por oceanos ou desertos, álcool e vagabundagem no frio. Trata-se aqui de tentativas para não depender do objeto de amor, já que o investimento e a dominação são deslocados sobre um objeto não vivo.

Ao deslocar seu investimento para objetos quentes, que podem lhe proporcionar um calor imediato que se acredita ter sob controle, o sujeito não é confrontado com suas necessidades, suas faltas, ao mesmo tempo em que ele acredita estar protegido de ser "largado", abandonado. Também pode acontecer de os pais "coisificarem" o filho, estabelecendo um vínculo com um ser não reconhecido no seu desejo, portanto, um ser inerte.

Mas poder-se-ia colocar a questão de um outro nível de funcionamento: existiria um ômega somático? Sim, afirma Decherf, pois às vezes o sujeito, em vez 
de construir um universo perigoso, relacionado com as falhas da continência, utilizaria seu próprio corpo para exprimir esse perigo. Assim, no ômega somático, o sujeito careceria de continência psíquica, ficando impedido de realizar transformações e superar vivências traumáticas, atualizando em seu corpo uma ameaça mortal, desenvolvendo doenças graves, como a obesidade mórbida.

\section{Percursos de vida: histórias de privação}

Treze casos foram atendidos para avaliação psicodiagnóstica, ao longo de um período de dois anos, a partir de encaminhamentos feitos por Serviço de $\mathrm{Nu}$ trição de hospital universitário público, correspondendo a onze mulheres e dois homens, de idade entre 25 e 54 anos. Estas pessoas, apesar de submetidas a tratamento nutricional há alguns anos, não apresentavam resultados significativos e estavam para ser desligadas do programa assistencial para tornar viável a reabertura da porta de entrada a novos pacientes.

A avaliação psicodiagnóstica, realizada com os referidos pacientes, constou em média de seis sessões e os procedimentos utilizados foram entrevistas clínicas semidirigidas (Bleger, 1971) e aplicação de testes projetivos. Para este trabalho, foram utilizadas apenas as histórias dos pacientes conforme relatadas por eles durante as entrevistas, cujo conteúdo foi registrado por escrito, pós-sessão, e depois analisado a partir do referencial psicanalítico.

Tais histórias revelam muito sofrimento, decorrente de maus-tratos na infância e da falta de compreensão quanto a suas necessidades afetivas e condição psíquica. Isto acarretou consequências nocivas em diversas áreas de suas vidas, inclusive com a reprodução de situações de violência em diferentes contextos: conflitos familiares e conjugais, baixa autoestima, estados de privação, falta de autonomia, incapacidade para estabelecer vínculos significativos, bem como para trabalhar e concluir projetos, dependência financeira, isolamento, insatisfação com a vida. São apresentadas, a seguir, quatro dessas histórias, que evidenciam como a violência familiar promove a função ômega, inclusive na sua expressão somática.

Ao falar sobre seu pai, Alice, 31 anos, IMC 43,59, assinala que ele era usuário de álcool e drogas, instável, brigava por qualquer motivo, agredindo fisicamente a mulher e os filhos. Na ausência da mãe, as crianças trancavam-se no banheiro para tentar escapar das surras. A mulher queria se separar do marido levando consigo os filhos, mas como era ameaçada de morte, voltava para casa com medo. A separação acabou por se dar quando Alice tinha 14 anos e ela só retornou a ver o pai quando já estava casada e com o filho caçula bebê. Posteriormente, o pai 


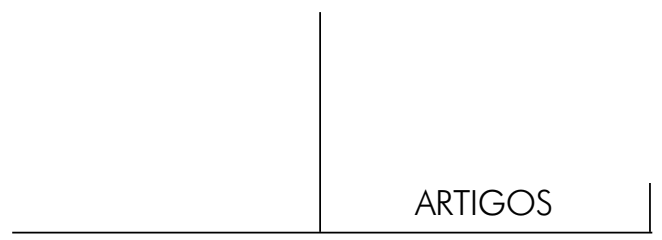

foi assassinado e enterrado como indigente. Segundo Alice, "ele desperdiçou tudo pelo vício".

A violência doméstica experienciada na infância, ainda mais quando de forma repetitiva, como um padrão familiar, tem efeitos deletérios cumulativos e permanece como um trauma ativo no psiquismo (Almeida Prado e Féres-Carneiro, 2005), promotor de novas situações violentas. Assim, Alice refere a sua atual relação com os irmãos como conflituosa, marcada por brigas e intrigas, e a seu próprio comportamento como impulsivo e violento: chegou a expulsar o pai à faca de sua casa e quis atear fogo no marido. Com baixa escolaridade (ensino fundamental incompleto), casou-se aos 16 anos, nunca alcançou autonomia e é dependente financeiramente.

Outra forma de violência diz respeito a estados de privação, conforme nos relata Bertha, 54 anos, IMC 41,01. Filha do meio de uma prole de cinco, era a única menina. $\mathrm{O}$ pai, descrito como rígido, porém carinhoso, foi referido como mantenedor e a mãe não podia trabalhar fora. Relata sua infância como boa, assinalando que não tinham luxos, mas nunca faltou comida em casa. Afirma que sua única ressalva é ter sido muito presa por causa do pai. Pôde cursar apenas até a $5^{\mathrm{a}}$ série do antigo curso primário, concluída com 11-12 anos, e não fez o ginásio porque o pai não permitiu. Ele dizia que "mulher não precisa saber mais do que ela já sabia". Não retornou aos estudos posteriormente. Embora tenha feito curso de corte e costura, seu pai nunca permitiu que fizesse trabalhos para fora.

A situação abusiva do pai, na verdade extremamente agressiva quanto às possibilidades de crescimento pessoal de Bertha e a sua condição de sujeito, diz respeito à violência psicológica disfarçada como "proteção". A figura paterna se mantém extremamente idealizada e, desta forma, procura evitar o ódio pelo pai castrador e pela mãe não protetora, ela própria também submissa e impotente. Bertha se apresenta identificada com o agressor, pois apesar do sofrimento presente em seu relato, devido aos estados de privação aos quais se viu submetida, comentou que, se tivesse tido uma filha, faria com ela o mesmo que seu pai fizera consigo, por "proteção".

Bertha relatou suas imensas dificuldades em lidar com situações de luto e perda, vividas como desorganizadoras. As perdas na infância foram imensas, com a proibição paterna de frequentar a escola, de ter amigos e de se profissionalizar. Casou-se aos 14 anos, com um homem doze anos mais velho do que ela. Descreve-se como impulsiva e violenta, sem autonomia e dependente financeiramente. Sempre engordando em situações de conflito, vê-se às voltas com vivências depressivas e ideias recorrentes de suicídio. Quando em crise, "refugia-se" nos doces para se acalmar, principalmente leite condensado. Seu destino, conforme suas palavras, é ser gorda e "burra", e "pilotar o fogão". 
Eduardo descreve-se como impulsivo e dado a excessos, como comer e beber muito, a qualquer momento. Com 42 anos, IMC 41,46, é o filho mais velho de uma prole de dois. Demonstrou dificuldades em falar sobre sua infância junto aos pais, descrevendo como distanciadas as relações entre eles. Os pais são referidos como ausentes ao longo de seu desenvolvimento, o que fez com que tenha sido praticamente criado pelos avós paternos e maternos. O pai, descrito como muito severo, brigava e gritava com os filhos. Relata que a mãe, muito tensa, apressava-o em tudo o que ele fazia. Tanto a infância quanto a adolescência foram descritas como desprivilegiadas devido à dinâmica familiar, com muita privação afetiva.

Percebia um tratamento diferenciado dado aos filhos pelos pais: enquanto ele se via sempre beneficiado, seu irmão era tratado com impaciência. Contudo, relatou que tanto os pais quanto o irmão o depreciavam muito e ele costumava bater no irmão, descontando nele as brigas dos pais com ele. Ainda assim, era com ele que tinha alguma cumplicidade. Passou a fazer uso de bebida desde os nove anos, consentido pelo pai, também usuário. Comentou que os membros da família bebiam muito, inclusive o pai, embora não os considerasse alcoólatras.

Os relatos de Eduardo retratam uma dinâmica familiar particularmente oscilante e instável (pais "pêndulos"), com pais incapazes de oferecerem suficiente sustentação afetiva e psíquica. Ao mesmo tempo em que é referida uma excessiva severidade por parte do pai, é assinalada uma desconcertante permissividade, com ele autorizando o consumo de bebidas alcoólicas a um menino de nove anos. Evidentemente, tratava-se de pais sem noção das necessidades e conveniências de uma criança. Eduardo, obeso, usuário de álcool e drogas, permaneceu sempre dependente dos pais, sem nenhuma autonomia e incapaz de trabalhar ou de concluir projetos.

Incapaz de estabelecer vínculos significativos, nunca se casou nem manteve relação estável com nenhuma pessoa. Refere namoro superficial com moça que vivia deprimida e que veio a cometer suicídio. Depois dessa namorada, passou a recorrer a prostitutas para suprir suas necessidades sexuais. Mencionou tratar-se de relações cheias de "promiscuidade", evitando falar mais sobre o assunto. $\mathrm{Na}$ verdade, considerava que o que conseguira na vida foi "uma cachorra e três gatos".

Fernando, 37 anos, IMC 43,82, é o filho mais velho de uma prole de dois. Nunca conheceu o pai, que era português. O que sabe sobre ele se deve a relatos da mãe e da avó, que diziam que o pai pretendia raptá-lo. Contudo, comenta-se, em família, que o pai desconfiava de sua paternidade, que registrara o filho visando receber benefício (dinheiro), abandonando a família quando o menino tinha seis dias. Comenta que sempre foi responsabilizado por sua mãe pelo abandono do companheiro, pelo fato de ter nascido. 


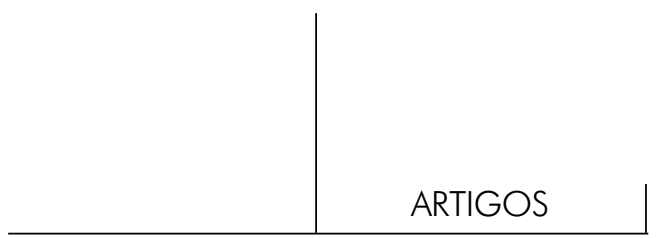

Foi criado pelos avós, pela mãe e por um tio. Assim, os avós eram como seus pais, mãe e tio, como irmãos, com os quais se via em disputas fraternas. Desta forma, as gerações se confundiam, sendo uma abolida. Refere a sua infância como sendo muito tumultuada, com brigas frequentes entre os familiares, sem respeito pelos direitos alheios, situação que perdura até o presente. Quando criança, tinha a fantasia de se tornar um super-herói para impor a sua vontade à família.

Aos oito anos, sua mãe passou a viver com outro homem, cujo contato com Fernando foi relatado como muito impessoal. Ele próprio demonstrou dificuldades para se lembrar de vivências com o padrasto. Desta união nasceu-lhe uma irmã, quando ele contava nove anos, fato abordado como "a perda do pouco do sossego que tinha". De acordo com seu relato, ela podia mexer em suas coisas, fazer o que quisesse, e ele não tinha o direito de se manifestar, sendo punido com castigos. Diz ter sofrido um, aos dez anos, particularmente severo, aplicado pelo avô e motivado por intrigas da mãe.

$\mathrm{Na}$ adolescência, os conflitos familiares mantiveram-se intensos. Aos 16 anos, começou a praticar judô e jiu-jítsu, como uma forma de "descarregar" os problemas. Diz nunca ter perdido uma luta; via o adversário como responsável por seus problemas e seu objetivo era surrá-lo. Passou a praticar intensa atividade física visando definição corporal, socando os mamilos com o objetivo de "tonificar os músculos e enrijecê-los". Por falta de tempo, parou de lutar ao ingressar na faculdade e começar a trabalhar. A seu ver, a luta sendo sua forma de "descarga" dos afetos, a alternativa que encontrou foi comer compulsivamente.

Assinalou que a família inteira reside em um lote que pertencia à avó e que foi subdividido em terrenos com diferentes casas. Apenas uma prima mora afastada da família. Contou que obteve informação sexual com amigos e que sua iniciação sexual se deu com a namorada. Refere a sua vida afetiva como sendo muito tumultuada, envolvendo-se com mulheres descritas como muito complicadas, o que acarretava vários conflitos. Com a atual noiva, tem muitas discussões, assinalando que ela seria uma excelente companheira "se tivesse miolo". A seu ver, seus relacionamentos afetivos sempre acabavam porque sua família atrapalhava, "fazendo a cabeça delas", da mesma forma que a mãe "fizera a cabeça" do avô contra ele, que, semelhante a ela, responsabilizava um outro pelos seus fracassos conjugais, como ela fizera com o próprio filho.

Trabalhava como professor contratado de Matemática e Física, no ensino fundamental e médio, dava aulas particulares e fazia reparos em aparelhos eletrônicos, mas se sentia sem autonomia, por ganhar pouco, em trabalhos que não lhe davam estabilidade. Nos grupos profissionais e sociais, tendia a ficar isolado. Disse não suportar injustiças, nem que mexessem com ele, com brincadeiras e chacotas. 


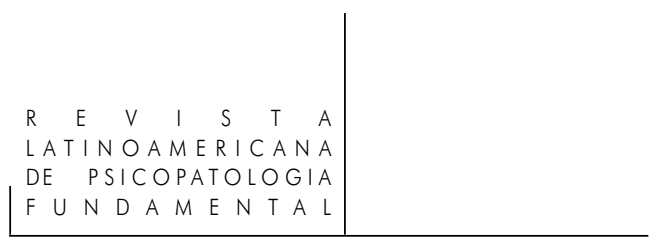

\section{Considerações finais}

A violência familiar e os maus-tratos na infância, com seus efeitos deletérios, perturbadores e profundamente desorganizadores, permearam as histórias de vida relatadas, tanto no que diz respeito à relação conjugal dos pais quanto àquela que mantinham com seus filhos, com reflexos negativos para o futuro afetivo-sexual dos mesmos. A violência, enquanto passagem ao ato, assinala a insuficiência da capacidade de simbolizar a experiência e de transformá-la, e impede que o próprio corpo e as atividades psíquicas sejam vividos com prazer.

Observou-se uma tendência à reprodução da violência nas relações conjugais e familiares que os sujeitos vieram a estabelecer, ou então a ausência de relacionamentos significativos em decorrência de retraimento e indisponibilidade afetivos. Em duas situações, os filhos eram tidos como "companheiro" ou "conselheira" da mãe, o que parece indicar uma postura regressiva, dependente e infantil, assim como a confusão de papéis.

Nas famílias dos obesos mórbidos, a continência psíquica se dá de forma precária e a vida relacional se caracteriza por vínculos de sobrevivência, sem autonomia, sendo acionadas defesas próprias à função ômega contra intensas angústias de morte. Seus membros denotam dificuldades que se repetem encadeadas em sucessivas gerações, inclusive com a presença do próprio quadro de obesidade e comorbidades correlatas, bem como pelo uso de álcool e/ou drogas. Desta forma, vê-se que a mediação se apresenta insuficiente, com intolerância e falta de confiança.

Foram observados, assim, déficits na capacidade de simbolização e impedimentos expressivos para a elaboração e transformação das situações vividas, com suas frustrações, ambivalências e conflitos diversos, pela ausência de continência psíquica e de recursos internos mediadores. Trata-se de famílias caracterizadas por um ômega patológico, que favorece a proximidade psíquica com a morte e construções defensivas que envolvem formas de agir e passagens ao ato.

Na obesidade mórbida, as perturbações na continência psíquica ou sua carência, as falhas na capacidade de ligação e de desligamento e nos processos de transformação promovem sofrimentos psíquicos próprios às patologias dos "estados-limite", que dizem respeito à transmissão da vida psíquica entre as gerações. Nelas estão comprometidos o narcisismo, o originário e a simbolização primária, portanto, o vínculo intersubjetivo, de forma que as experiências não são reconhecidas em seu significado emocional.

Se a continência familiar é "fria", sem acolhimento e sem respostas às necessidades emocionais e relacionais do sujeito, dá-se a busca à continência "quente" como uma tentativa de não depender do objeto de amor. Ao se investir em um 


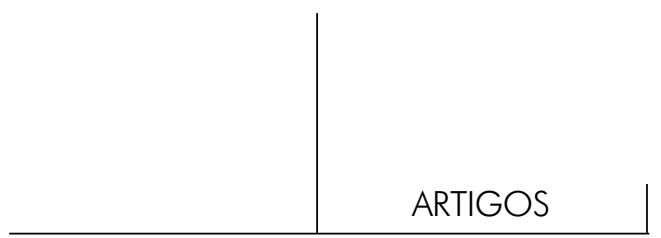

objeto não vivo, inerte como o álcool, as drogas e a comida, acredita-se tê-lo sob controle, com o fornecimento de um calor imediato.

Nas histórias de vida dos obesos mórbidos avaliados neste estudo, observou-se que seus objetos de amor se apresentam precários ou inexistentes, de forma que seus investimentos são deslocados sobre um objeto não vivo, inerte. Contudo, o inerte também envolve outras significações, como assinala Decherf (2003), tais como objetos fetiches e imagens pornográficas que têm a vantagem de serem utilizados e descartados a seguir, evitando-se assim qualquer dependência. Quando não há segurança nem continência que sustentem vínculos de dependência, a comida, procurada enquanto objeto quente, acaba por transformar-se em fezes descartáveis, com as quais também são evacuadas as experiências emocionais.

A obesidade mórbida é entendida como uma patologia dos estados-limite, que diz respeito ao ômega somático. Trata-se de uma doença grave e mortífera na qual o corpo é utilizado para expressar o perigoso universo psíquico em que se encontra o sujeito, devido às falhas de continência.

Almeida-Prado, M. C. C.; Féres-Carneiro, T. Abuso sexual e traumatismo psíquico. Interações, São Paulo, v. 10, n. 20, p. 11-34, 2005.

Benedetti, C. De obeso a magro: a trajetória psicológica. São Paulo: Vetor, 2003.

Bentovim, A. Trauma organised systems. Physical and sexual abuse in families. London/New York: Karnac Books, 1992.

Bion, W. R. (1967). Estudos psicanalíticos revisados. Rio de Janeiro: Imago, 1988.

Bleger, J. (1971). Temas de psicología. Entrevistas y grupos. Buenos Aires: Nueva Visión, 1977.

Brette, F. (2002). Verbete traumatismo real. In: Mijolla, A. (Org.). Dicionário internacional da psicanálise: conceitos, noções, biografias, obras, eventos, instituições. Rio de Janeiro: Imago, 2005. p. 1930-1931.

Caillot, J.-P.; Decherf, G. Thérapie familiale psychanalytique et paradoxalité. Paris: Clancier-Guénaud, 1982.

Carneiro, M. I. E. Um crime parental: possíveis desdobramentos de abusos sexuais em filhos. Revista Brasileira de Psicanálise, Rio de Janeiro, v. 39, n. 2, p. 135-142, 2005.

Decherf, G. Souffrances dans la famille. Thérapie familiale psychanalytique d' aujourd' hui. Paris: In Press, 2003. 
Freud, S. (1912). A dinâmica da transferência. In: Edição Standard Brasileira das Obras Psicológicas Completas de Sigmund Freud. Rio de Janeiro: Imago, 1975. v. XII, p. 133-143.

. (1916-1917). Conferências introdutórias sobre psicanálise (Conferência XVIII). In: Edição Standard Brasileira das Obras Psicológicas Completas de Sigmund Freud. Rio de Janeiro: Imago, 1976. v. XVII, p. 323-336. . (1920). Além do princípio de prazer. In: Edição Standard Brasileira das Obras Psicológicas Completas de Sigmund Freud. Rio de Janeiro: Imago 1975. v. XVIII, p. 17-85. . (1939). Moisés e o monoteísmo. In: Edição Standard Brasileira das Obras Psicológicas Completas de Sigmund Freud. Rio de Janeiro: Imago, 1975. v. 23, p. 19-161. Gabel, M. et al. Le traumatisme de l'incest. Paris: Presses Universitaires de France, 1995.

GASPAR, F. M. P. Obesidade e trabalho: histórias de preconceito e reconhecimento vividas por trabalhadores obesos. São Paulo: Vetor, 2003.

KAËs, R. Os espaços psíquicos comuns e partilhados: transmissão e negatividade. São Paulo: Casa do Psicólogo, 2005.

KLein, M. (1963). Nosso mundo adulto e suas raízes na infância. In: KLEIN, M. $O$ sentimento de solidão. Rio de Janeiro: Imago, 1975. p. 23-48.

Loli, M. S. A. Obesidade como sintoma: uma leitura psicanalítica. São Paulo: Vetor, 2000.

Racamier, P.-C. Perversion narcissique dans la famille du psychotique. Dialogue, Paris, v. 99, p. 32-41, 1988.

Rosenfeld, H. A. (1965). Da psicopatologia do narcisismo: uma aproximação clínica. In: Rosenfeld, H. A. (Org.). Os estados psicóticos. Rio de Janeiro: Zahar, 1968. p. 193-204.

. (1987). Impasse e interpretação. Rio de Janeiro: Imago, 1988.

. A clinical approach to the psychoanalytic theory of the life and death instincts: an investigation into the aggressive aspects of narcissism. The International Journal of Psychoanalysis, New York, v. 52, p. 169-178, 1971.

Rouyer, M. (1992). As crianças vítimas, consequências a curto e médio prazo. In: Gabel, M. (Org.). Crianças vítimas de abuso sexual. São Paulo: Summus, 1997. p. 62-71.

RufFiot, A. Le groupe-famille en analyse. L' appareil psychique familial. In: RufFiot, A. et al. (Orgs.). La thérapie familial psychanalytique. Paris: Dunod, 1981, 1-98.

STEINER, J. (1993). Refúgios psíquicos: organizações patológicas em pacientes psicóticos, neuróticos e fronteiriços. Rio de Janeiro: Imago, 1997. 


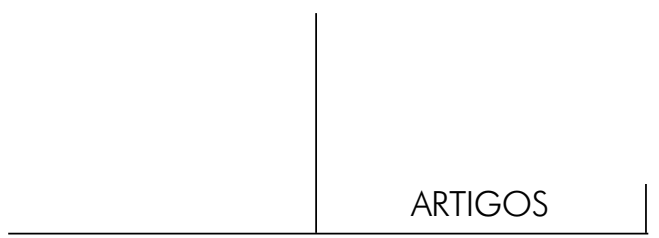

Resumos

(Family violence: morbid obesity and the omega function)

This study explores the psychological aspects of morbidly obese patients, based on thirteen cases that received psychodiagnostic evaluation. Their life stories, as recounted by them during the interviews, are taken up in the article. The material collected was put down in writing after the sessions, and later analyzed from a psychoanalytical perspective. The author concludes that morbid obesity is a pathology of limit states, related to the somatic omega, where disturbances are presented in the psychological continence and processes of transformation.

Key words: Morbid obesity, omega function, family violence, psychic transmission

(La violence au sein de la famille: l'obésité morbide et la fonction oméga)

La présente étude se propose d'interroger certains aspects psychologiques relatifs aux obèses morbides à partir de treize cas de patients observés en évaluation psychodiagnostique. Nous avons utilisé à cette fin leurs histoires de vie, telles qu'elles nous ont été relatées par les patients au cours des entrevues. Le matériel recueilli a été analysé en fonction du référentiel psychanalytique. Il en a été conclu que l'obésité morbide est une pathologie des états-limites affectant l'oméga somatique et caractérisée par des troubles dans la contenance psychique et dans les processus de transformation. Mots clés: Obésité morbide, fonction oméga, violence familiale, transmission psychique

(Violencia familiar: obesidad mórbida e función omega)

Este estudio tiene como objetivo examinar los aspectos psicológicos de obesos mórbidos. La investigación se ha basado en trece casos, en los que ha sido realizada una evaluación psicodiagnóstica. Han sido utilizadas las historias de vida de los participantes, relatadas durante las entrevistas. El material recogido fue analizado a partir de la teoría psicoanalítica. Se concluye que la obesidad mórbida es una patología de los estados limítrofes de la personalidad, que se refieren al "omega somático", en que hay perturbaciones en la continencia psíquica y en los procesos de transformación.

Palabras clave: Obesidad mórbida, violencia familiar, función omega, transmisión psíquica

Citação/Citation: Almeida Prado, M.C.C.; Féres-Carneiro, T. Violência familiar: obesidade mórbida e função ômega. Revista Latinoamericana de Psicopatologia Fundamental, São Paulo, v. 12, n. 2, p. 190-206, jun. 2010.

Rev. Latinoam. Psicopat. Fund., São Paulo, v. 13, n. 2, p. 190-206, junho 2010 


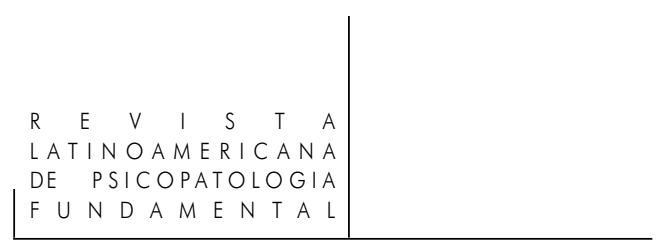

Editor do artigo/Editor: Prof. Dr. Manoel Tosta Berlinck

Recebido/Received: 31.5.2009 / 5.31.2009 Aceito/Accepted: 18.8.2009/8.18.2009

Copyright: ( $) 2009$ Associação Universitária de Pesquisa em Psicopatologia Fundamental/ University Association for Research in Fundamental Psychopathology. Este é um artigo de livre acesso, que permite uso irrestrito, distribuição e reprodução em qualquer meio, desde que $o$ autor e a fonte sejam citados/This is an open-access article, which permits unrestricted use, distribution, and reproduction in any medium, provided the original author and source are credited.

Financiamento/Funding: As autoras declaram não terem sido financiadas ou apoiadas/The authors have no support or funding to report.

Conflito de interesses/Conflict of interest: As autoras declaram que não há conflito de interesses/The authors declare that has no conflict of interest.

\section{Maria do Carmo Cintra de Almeida-Prado}

Doutorado em Psicologia Clínica pela Pontifícia Universidade Católica do Rio de Janeiro PUC-Rio (Rio de Janeiro, RJ, Brasil); pós-doutorado em Psicologia Clínica pela Pontifícia Universidade Católica do Rio de Janeiro - PUC-Rio; psicóloga do Instituto de Psicologia da Universidade do Estado do Rio de Janeiro - UERJ (Rio de Janeiro, RJ, Brasil); coordenadora dos Setores de Terapia de Família e de Psicodiagnóstico da Unidade Docente Assistencial de Psiquiatria do Hospital Universitário Pedro Ernesto (Rio de Janeiro, RJ. Brasil); membro associado da AP Rio 3 e da IPA, bem como da AIPCF

Av. Rainha Elizabeth da Bélgica, 650/702

22081-030 Rio de Janeiro, RJ, Brasil

Fone: (21) 2247-7810

e-mail: cintradealmeidaprado@yahoo.com.br

\section{Terezinha Féres-Carneiro}

Professora titular do Departamento de Psicologia da Pontifícia Universidade Católica do Rio de Janeiro - PUC-Rio (Rio de Janeiro, RJ, Brasil).

Rua General Góes Monteiro, 8 - bloco D, apto. 2403

22290-080 Rio de Janeiro, RJ, Brasil

Fone: (21) 2285-2546

e-mail: teferca@puc-rio.br 